\title{
What is the Role of Pediatricians on Oral Health?
}

\author{
Cigdem Elbek Cubukcu \\ Uludag University, School of Medicine, \\ Consultation Unit of Oral Diseases, \\ Turkey
}

\section{Introduction}

Good oral health and dentition is important for efficient mastication, speaking and cosmetically for smiling. If left untreated, dental pathologies can lead to pain and infection, reduced growth and development, speech disorders, and high treatment costs. Chronic infection around one or more teeth can result in damage to localized structures, such as the developing permanent teeth. Children who are medically compromised (such as being immunocompromised from a disease and/or therapy) are at increased risk of developing systemic complications from dental infections which can be fatal. Therefore, the author focuses on the role of the general pediatrician in promoting the importance of good oral health for all children and in particular those children receiving cancer therapy. Etiology, assessment, and prevention of dental caries and oral mucositis are presented, evidence based where available.

\section{Dental caries development}

Dental caries has historically been considered one of the most important global oral health burdens. It is still a major health problem in both developing and developed countries. $60-90 \%$ of school-aged children are affected by the disease (Petersen, 2003). At present, the distribution and severity of dental caries vary in different parts of the world and within the same region or country. In permanent dentition, when dental caries experience is expressed as Significant Caries Index $(\mathrm{SiC})$, the determined values are relatively high both for America region $(\mathrm{SiC}=$ $4.8)$ and the European region $(\mathrm{SiC}=5.3)$ whereas the experience is lower in most African countries $(\mathrm{SiC}=3.4)$ (World Health Organization [WHO], 2011). In developing countries, the prevalence rates of dental caries and its experience are now tending to increase probably due to the increasing consumption of sugars and inadequate exposure to fluorides. Conversely, a decline in caries has been observed in most developed countries as a result of a number of public health measures, including effective use of fluorides, together with changing living conditions, lifestyles and improved self-care practices. However, it must be emphasized that dental caries as a disease of children has not been eradicated, but only controlled to a certain degree.

\subsection{Etiology of dental caries}

Dental caries is a process that may take place on any tooth surface in the oral cavity where dental plaque (biofilm) is allowed to develop over a period of time. Plaque formation is a 
natural, physiological process. It is an example of a biofilm which means a community of microorganisms attached to a surface. The bacteria in the plaque are always metabolically active. Some of them are capable of fermenting a suitable dietary carbohydrate substrate (such as the sugars sucrose and glucose), to produce acid. The acid produced causes the plaque $\mathrm{pH}$ to fall to below 5 within 1-3 minutes. Repeated falls in $\mathrm{pH}$ may result in demineralization of the tooth surface in time. However, the acid is neutralized by saliva, so the $\mathrm{pH}$ increases and mineral may be regained. This is called remineralization. The cumulative results of de- and remineralization processes may be a loss of mineral and a carious lesion can be seen. Alternatively, the changes may be so slight that a carious lesion never becomes apparent (Kidd, 2005). The formation of the biofilm and its metabolic activity cannot be prevented, but dental caries formation can be controlled, its progression in enamel tissue can be arrested and even advanced carious lesions (in dentin) may become inactive.

\subsection{Factors known to influence increased dental caries risk}

Socio-economic factors or circumstances may influence increased caries risk. Factors such as social deprivation, unemployment, lower socio-economic status, low knowledge, low education of parents, and no regular dental check-ups are directly related to dental caries resulting in more cariogenic food consumption, less good oral hygiene, saliva problems (medications), and reduced fluoride support (WHO, 1994).

General health may also indicate increased caries risk. Some general diseases such as Sjögren's Syndrome or their treatments (medicines) affect saliva secretion. Also, the conditions can result in more cariogenic food and in less good oral hygiene (WHO, 2003).

Medicines can interfere with dental caries in two ways by leading to voluminous plaqueformation (containing fermentable carbohydrates) and by leading to a change in saliva production and composition. Medicines classified as follows have been proposed to cause xerostomia (oral dryness): antispasmodic, antidepressant, antipsychotic, skeletal muscle relaxant, parkinsonism therapy, antiarrythmic, antihistamine, appetite depressant, anticonvulsant, anxiolytic, antihypertensive, and diuretic. Oral dryness is the third most common side-effect from using medicines (Moore, 2008).

Diet is one of the key factors for dental caries and will be discussed in detail on section 4.1.

\section{Assessment of dental development and referral for dental problems}

Accurate chronologies of primary (deciduous) teeth calcifications as well as permanent dentition in particular first permanent molars are of clinical significance to the pediatricians (Table 1 and 2). It is often necessary to explain to parents the time sequence of calcification in utero and during infancy. The common observation of tetracycline pigmentation, developmental enamel defects, and generalized hereditary anomalies can be explained if the calcification schedule is known.

\subsection{Chronologic development and eruption of the teeth}

Evidence of development of the human tooth can be observed as early as the sixth week of embryonic life. Its life starts with initiation (bud stage) and follows with proliferation (cap stage), histodifferentiation and morphodifferentiation (bell stage), apposition, and 


\begin{tabular}{|c|c|c|}
\hline \multicolumn{3}{|c|}{ Upper Primary Teeth Development Chart } \\
\hline Upper Teeth & When tooth emerges & When tooth falls out \\
\hline Central incisor & 8 to 12 months & 6 to 7 years \\
\hline Lateral incisor & 9 to 13 months & 7 to 8 years \\
\hline Canine (cuspid) & 16 to 22 months & 10 to 12 years \\
\hline First molar & 13 to 19 months & 9 to 11 years \\
\hline Second molar & 25 to 33 months & 10 to 12 years \\
\hline Lower Teeth & When tooth emerges & When tooth falls out \\
\hline Second molar & 23 to 31 months & 10 to 12 years \\
\hline First molar & 14 to 18 months & 9 to 11 years \\
\hline Canine (cuspid) & 17 to 23 months & 9 to 12 years \\
\hline Lateral incisor & 10 to 16 months & 7 to 8 years \\
\hline Central incisor & 6 to 10 months & 6 to 7 years \\
\hline
\end{tabular}

Table 1. Eruption and exfoliation timetable of primary human dentition. The first teeth begin to break through the gums at about 6 months of age. Usually, the first two teeth to erupt are the two bottom central incisors (the two bottom front teeth). Next, the top four front teeth emerge. After that, other teeth slowly begin to fill in, usually in pairs -- one each side of the upper or lower jaw -- until all 20 teeth (10 in the upper jaw and 10 in the lower jaw) have come in by the time the child is $2 \frac{1 / 2}{2}$ to 3 years old.

\begin{tabular}{|c|c|}
\hline \multicolumn{2}{|c|}{ Upper Permanent Teeth Development Chart } \\
\hline Upper Teeth & When tooth emerges \\
\hline Central incisor & 7 to 8 years \\
\hline Lateral incisor & 8 to 9 years \\
\hline Canine (cuspid) & 11 to 12 years \\
\hline $\begin{array}{c}\text { First premolar } \\
\text { (first bicuspid) }\end{array}$ & 10 to 11 years \\
\hline Fecond premolar (second bicuspid) & 10 to 12 years \\
\hline First molar & 6 to 7 years \\
\hline Second molar & 12 to 13 years \\
\hline Third molar (wisdom teeth) & 17 to 21 years \\
\hline Lower Permanent Teeth Development Chart \\
\hline Lower Teeth & When tooth emerges \\
\hline Third molar (wisdom tooth) & 17 to 21 years \\
\hline Second molar & 11 to 13 years \\
\hline First molar & 6 to 7 years \\
\hline Second premolar (second bicuspid) & 11 to 12 years \\
\hline $\begin{array}{c}\text { First premolar } \\
\text { (first bicuspid) }\end{array}$ & 10 to 12 years \\
\hline Canine (cuspid) & 9 to 10 years \\
\hline Lateral incisor & 7 to 8 years \\
\hline Central incisor & 6 to 7 years \\
\hline
\end{tabular}

Table 2. Eruption and exfoliation timetable of permanent human dentition. Permanent teeth begin to come in around the age of 6 . In some children, the first permanent molars are the first to emerge; in others, the incisors are the first to emerge. 
calcification (AlQahtani et al., 2010). Ameloblasts will form enamel whereas odontoblasts will form dentin tissue. Following completion of all these stages the tooth will erupt. Primary teeth will shed (exfoliate) to their permanent successors. Although many theories have been advanced (Marks Jr., 1996; Philbrick et al., 1998; Wise et al., 2002), the factors responsible for the eruption of the teeth are not fully understood. The factors that have been related to the eruption of teeth include elongation of the root, forces exerted by the vascular tissues around and beneath the root, growth of the alveolar bone, growth of dentin, growth and pull of the periodontal membrane, hormonal influences (pituitary growth hormone, thyroid hormone, and parathyroid hormone-related protein), presence of a viable dental follicle, pressure from the muscular action, and resorption of the alveolar crest. A review article by Wise et al (Wise et al., 2002) focused on the molecular signals that initiate tooth eruption. They stated that tooth eruption is a complex and tightly regulated process involving cells of the tooth organ and surrounding alveolus. Mononuclear cells (osteoclast precursors) must be engaged into the dental follicle prior to the onset of eruption. These cells will turn into osteoclasts which resorb alveolar bone, and create an eruption pathway for the tooth to exist its bony container. Interaction of osteoblasts, osteoclasts and dental follicle involve a complex interplay of regulatory genes. It should be remembered that the time of eruption of both primary and permanent teeth varies greatly and variations of 6 months on either side of the usual eruption date may be considered normal for a given child. Demirjian and Levesque (1980) investigated a large sample of 5437 radiographs from a homogenous French-Canadian population, their analysis showed the similarity in timing between sexes for the early stages of tooth development (crown formation). However, their data indicated the importance of sexual dimorphism during the period of root development which girls were more advanced than boys by an average of 0.35 year for four teeth. For the stages of root development the mean difference between the sexes for all teeth was 0.54 year. The largest difference was for the canine ( 0.90 year). A study by Proffit and Fraizer-Bowers (2009) reviews the mechanism and control of tooth eruption. Finally an extensive review by Almonaitiene et al. (2010) analyzed the factors influencing permanent teeth eruption. Readers who wish to obtain more information about the details of the tooth eruption process are referred to these review articles.

\subsection{Teething and difficult eruption}

In general, the eruption of primary teeth comes before by increased salivation, and the child would want to put the hands and fingers into the mouth. Some young children become daytime restlessness, an increase in the amount of finger sucking or rubbing of the gum, an increase in drooling and some loss of appetite during the time of eruption of the primary teeth. These observations may be the only indication that the teeth will soon erupt (Macknin et al., 2000; Feldens et al., 2010). However, in some children a pronounced change in the mucosa often with small hemorrhages could be expected (Tasanen, 1968). Many conditions including croup, diarrhea, fever, convulsions, and primary herpetic gingivostomatitis have been incorrectly attributed to eruption (Dally, 1996). Leung (1989) reported that serious mistakes could be made in the care of infants and toddlers if their symptoms were ascribed to teething without completion of a thorough diagnostic evaluation and resulted in the overlooking of significant systemic disturbances. Because of the tooth eruption is a normal physiologic process, the association with fever and systemic disturbances are not justified. Inflammation of the gingival tissues before complete eruption of the tooth crown may cause 
a temporary painful condition which relieves within a few days. The eruption process may be hastened if the child is allowed to chew on a clean teething object. Using finger press technique upon where the tooth has been emerging will subside the probably fretful condition. The application of a nonirritating topical anesthetic may bring in temporary relief in the child has been experiencing extreme difficulty during the teeth eruption (Sood \& Sood, 2010).

Primary teeth eruption facts for the pediatricians:

- A general rule of thumb is that for every 6 months of life, approximately 4 teeth will erupt

- Girls generally precede boys in tooth eruption

- Lower teeth usually erupt before upper teeth

- Teeth in both jaws usually erupt in pairs -- one on the right and one on the left Primary teeth are smaller in size and whiter in color than the permanent teeth that will follow

- By the time a child is 2 to 3 years of age, all primary teeth should have erupted Shortly after age 4 , the jaw and facial bones of the child begin to grow, creating spaces between the primary teeth. This is a perfectly natural growth process that provides the necessary space for the larger permanent teeth to emerge.

- Between the ages of 6 and 12, a mixture of both primary teeth and permanent teeth reside in the mouth

If baby teeth fall out after a couple of years, why is it important to care for them?

- They reserve space for their permanent counterparts

- They give the face its normal appearance

- They aid in the development of clear speech

- They help attain good nutrition (missing or carious teeth make it difficult to chew causing children to reject foods)

- $\quad$ They help give a healthy start to the permanent teeth (caries and infection in baby teeth can cause dark spots on the permanent teeth developing beneath it).

\subsubsection{Eruption hematoma (eruption cyst)}

A bluish purple, elevated area of tissue called an eruption hematoma rarely develops a few weeks before the eruption of a primary or permanent tooth. It is actually a blood-filled cyst. It occurs most frequently in the primary second molar or the first permanent molar regions. The condition usually develops as a result of trauma to the soft tissue during mastication. The condition is self-limited and usually subsides in a few days following the break-through of the crown. Therefore, the treatment of the hematoma is rarely necessary. In order to expose the crown, surgical incision of the gingival tissue may rarely be needed (Tsiklakis \& Patsakas, 1989).

\subsubsection{Eruption sequestrum}

The eruption sequestrum is seen occasionally at the time of eruption of the first permanent molar. It may develop from either osteogenic (Starkey \& Shafer, 1963) or odontogenic tissue (Watkins, 1975; Pridds \& Price, 1984). Regardless of its origin, the condition is usually of 
little or no clinical significance. As the tooth erupts, the fragment will sequestrate. However, it can be removed if it causes local irritation.

\subsubsection{Ectopic eruption}

A variety of local factors such as arch length inadequacy may influence a tooth to erupt or try to erupt in an abnormal position (Gupta et al, 2011).

\subsection{Natal and neonatal teeth (prematurely erupted primary teeth)}

The normal eruption of the primary teeth typically begins at six months of age. Natal teeth (teeth present at birth) and neonatal teeth (teeth that erupt during the first 30 days) are usually benign conditions (Cunha et al., 2001). Whatever the conditions they are, both of them considered as early eruption of primary teeth. Spouge and Feasby believe that the terms natal teeth and neonatal teeth constitute a relatively artificial distinction. Therefore, they have suggested that the terms mature and immature are more in keeping with the varying prognoses associated with such teeth in clinical point of view (Spouge \& Feasby, 1966). The incidence of natal teeth ranges from 1:2000 to 1:3500 live births (Seminario \& Ivancakova, 2004). The exact etiology is unknown. Infection, febrile states, trauma, malnutrition, superficial position of the tooth germ, hormonal stimulation and maternal exposure to environmental toxins has been implicated as causative factors (Cunha et al., 2001). It has been previously reported that heavily exposures to polychlorinated biphenyls and dibenzofurans caused to born infants with natal teeth in Taiwan (Gladen et al., 1990). However, Alaluusa et al. (2002) did not find any association between milk levels of polychlorinated biphenyls and dibenzofurans, and the occurrence of natal teeth. Early eruption of primary teeth might occur as a hereditary transmission of an autosomal dominant gene. A positive familial history has been reported in 8-62 \% of natal teeth cases (Zhu \& King, 1995). Natal teeth are present in $2 \%$ of infants with unilateral cleft lip and palate and $10 \%$ of infants with bilateral cleft lip and palate (de Almeida \& Gomide, 1996). Natal teeth have been reported in association with syndromes such as Ellis-van Creveld, Jadassohn-Lewandowsky, Hallerman-Streiff, craniofacial dysostosis, steacystoma multiplex, Sotos, Wiedemann-Rautenstrauch, Meckel-Gruber and Pierre Robin (Seminario \& Ivancakova, 1992; Uzamis et al., 1999; Marakoglu et al., 2004).

The most commonly affected teeth are the lower primary central incisors (85\%), followed by the maxillary incisors (11\%), mandibular canines and molars (3\%), and maxillary canines and molars $(1 \%)$. Natal teeth usually occur in pairs (Zhu \& King, 1995). However, an unusual case of an infant with fourteen natal teeth was reported by Masatomi et al. (1991). Natal teeth might resemble normal primary teeth in size and shape; however, the teeth are often smaller, conical and yellowish, and have hypoplastic enamel and dentin with poor or absent root development. Most prematurely erupted primary teeth are mobile because of limited root development. Some teeth may be supernumerary or mobile to the extent that there is danger of displacement of the tooth and possible aspiration. In such cases the removal (extraction) of the tooth is indicated. However, Zhu and King (1995) did not find any reported cases of aspirated natal or neonatal teeth in the literature. In some cases sharp incisal edge of the teeth may cause sublingual ulceration of the infant (Riga-Fede disease) or laceration of the mothers' breasts. If the teeth with rough edges are not hypermobile or not supernumerary; smoothing the sharp incisal edges of teeth or the placement of round smooth composite resin over the incisal edges is indicated. However, if the tooth does not 
interfere with breastfeeding or not hypermobile, no intervention is necessary. Consultation with a pediatric dentist is strongly recommended in order to evaluate the preferred treatment and for differential diagnosis. Eruption of teeth during the neonatal period causes fewer problems. These teeth can usually be maintained even tough root development is limited (Figure 1).

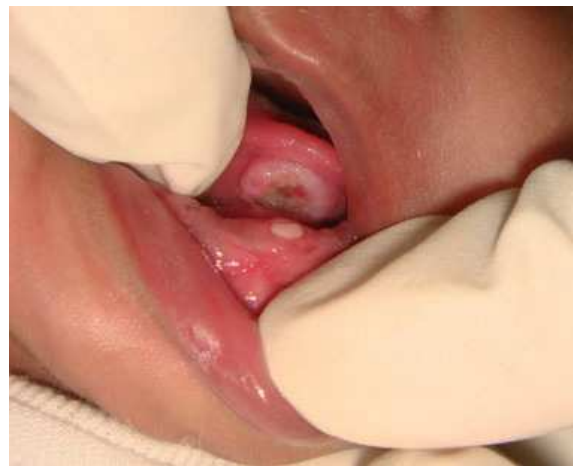

Fig. 1. Intraoral view showing a natal teeth and Riga-Fede disease (quoted from Padmanabhan et al. (2010) Neonatal sublingual traumatic ulceration - case report \& review of the literature. Dent Traumatol 26, 6, Dec, 490-5.)

\subsection{Epstein pearls, bohn nodules, and dental lamina cysts}

Small, white or grayish white lesions on the alveolar mucosa of the newborn are identified as inclusion cysts. They are classified as the following three types according to their location in oral cavity: Epstein pearls are formed along the midpalatine raphe. Bohn nodules are formed along the buccal and lingual aspects of the dental ridges and on the palate away from the raphe. Dental lamina cysts are found on the crest of the maxillary and mandibular ridges. These lesions are usually multiple but do not increase in size. No treatment is indicated since the lesions will spontaneously be shed a few weeks after birth. These lesions may be incorrectly diagnosed as the natal teeth (Fromm, 1967; Cetinkaya et al., 2011).

\subsection{Local and systemic factors that influence tooth eruption}

Local factors which influence tooth eruption are ankylosed primary and permanent teeth, and ankylosis of primary molars with absence of permanent successors. Local factors generally cause delayed teeth eruption (Ertugrul et al., 2002). Referral to a pediatric dentist is recommended for appropriate treatment.

General factors associated with altered tooth eruption are Down syndrome (Trisomy 21 syndrome), cleidocranial dysplasia, congenital hypothyroidism (Cretinism), juvenile hypothyrodism, hypopituitarism, and achondroplastic dwarfism. Sporadic delayed eruption of teeth frequently occurs in children with Down syndrome. The first primary teeth may not appear until 2 years of age, and the dentition may not be complete until 5 years of age. The eruption generally follows an abnormal sequence and some of the primary teeth may be retained until 15 years of age (Jara et al., 1993; Ondarza et al., 1997). The prevalence and severity of early onset periodontal disease in children with Down syndrome are much 
higher compared to normal healthy and other mentally disabled children. A high prevalence of necrotizing ulcerative gingivitis is also reported (Carlstedt et al., 1996; Cichon et al., 1998). These higher prevalence relating periodontal diseases cannot only be explained by poor oral hygiene alone and may be the result of impaired immune responses and deficient phagocytic systems (Morinushi et al., 1997). Dental caries susceptibility is usually low in those with Down syndrome (Davidovich et al., 2010). Cleidocranial dysplasia (osteodentin dysplasia) has dental significance. The patients exhibit mandibular prognathism. The maxilla tends to be short vertically but not in sagittal way. The development of the dentition is delayed. One of the distinguishing characteristics is the presence of supernumerary teeth (Richardson \& Deussen, 1994). The pediatric dentist serves as the coordinator of overall oral health care and disease prevention during an extended treatment regimen that usually includes two surgical interventions and three stages of orthodontic surgery. Hypothyroidism whether it occurs at birth or juvenile stage, causes delayed primary and permanent teeth eruption, and delayed primary teeth exfoliation (Mganga \& Chindia, 1990). Hypopituitarism also causes delayed teeth eruption. Primary teeth may not undergo resorption but instead retained throughout the life of the patient. The underlying permanent teeth will develop but do not erupt (Conley et al., 1990). Delayed teeth eruption has been linked to other disorders, such as fibromatosis gingivae, chondroectodermal dysplasia, Gardner syndrome.

\section{Provision of a caries control measurements}

\subsection{Cariogenic diet (reduction in the intake of freely fermentable carbohydrates)}

Diet refers to the habitual allowance of food and drink taken by any person from day to day. Thus, the diet may exert an effect on caries locally in the mouth by reacting with the enamel surface and by serving as a substrate for cariogenic microorganisms. The food per se does not cause dental caries. Diet operates via the bacteria and the result may be a low $\mathrm{pH}$ at which the tooth starts to dissolve. The role of diet for proper tooth formation is a separate issue.

The consumption of sugar in substantial amounts is a recent trend in many areas of the world. Evidence linking caries and sugar has been evaluated from communities with low sugar consumption, and the results from severe dietary restrictions in many countries since 1940s. Another piece of evidence linking diet and caries concerns the rare hereditary disease fructose intolerance, which is caused by an inborn error of metabolism. Ingestion of foods containing fructose or sucrose causes severe nausea because of lack a certain liver enzyme. Consequently children with this disease avoid to eat these foods. The caries experience of them is considerably low, indicating that a group of children who are not able to tolerate many sugary foods are unlikely to develop much caries. There have been a number of noninterventional studies and animal experiments to relate dietary habits to the high prevalence of dental caries. According to a WHO study group, very little caries occurs in children when the national consumption level of sugar is below $10 \mathrm{~kg}$ per caput per annum (i.e., about 30 $\mathrm{g} /$ day), but a steep increase may occur from $15 \mathrm{~kg}$ upwards (WHO, 2003). Interventional human studies also designed in Sweden and Finland. Dentists now base much of dietary advice on the results of these two interventional studies, indicating that the frequency of sugar intake should be reduced to confine sugar to meal times as much as possible. The goal is not to 
exclude sugar from the diet but rather to make the patient eat sugar in a sensible way sugar discipline (reasonable amounts and mainly at meal times). This also introduces the concept that it may be possible to substitute sucrose by substances which will impart sweetness but are not cariogenic, which is covered in more detail in section 4.3. However, a comparable study on human subjects will probably never be repeated as it would now be regarded as unethical to alter diets experimentally in directions likely to increase caries. Sugars integrated into the cellular structure of food (e.g. in fruit) are called intrinsic sugars. Sugars present in a free form (e.g. table sugar) or added to food (sweets, biscuits, etc.) are called extrinsic sugars. These are more readily available for metabolism by the oral bacteria. Therefore, they are potentially more cariogenic. Milk contains lactose. It is not generally regarded as cariogenic. Cheese and yoghurts, without added sugars, may also considered safe for teeth (Ahola et al., 2002). Bread, peanuts (not for children under 5 years), and sugarfree drinks are some examples of foods and drinks with low potential for dental caries. Thus the most damaging sugars for dental health are non-milk extrinsic sugars (NMES) (Moynihan, 2002). Both frequency and amount of sugars are associated with dental caries. However, at the level of the individual patient, it is more practical to advise limiting frequency of intake. Since frequency and amount of sugar consumed are closely associated and repeated sugar intakes mean several acid attacks on the teeth giving demineralization, efforts to reduce frequency should be made. Additionally, selecting food products that only lead a slight and/or short $\mathrm{pH}$ drop (above critical $\mathrm{pH}$ at which the enamel starts to dissolve around $\mathrm{pH}$ 5.5 ) is another measurement to reduce the unwanted local effects of diet with respect to caries. Many common food products containing fermentable carbohydrates can lead to a $\mathrm{pH}$ of about 4 after their consumption.

Raw starch (e.g. raw vegetables) is of low cariogenity. Cooked and highly refined (e.g crisps) can cause caries, and combinations of cooked starch and sucrose (e.g. cakes, biscuits, sugared breakfast cereals) can be highly cariogenic. Fruits contain sugar (fructose, sucrose, and glucose) but fresh fruits appear to have low cariogenity. However, the same cannot be said for fruit juice. The juicing process releases the sugars from the whole fruit, and these drinks are potentially cariogenic. Dried fruits are also cariogenic since they are sticky, tending to adhere to teeth, and the drying process releases some of the intrinsic sugars (Moynihan, 2002). Some children have particular risk to caries because of dietary factors. These children should at least sound warning bells in the pediatrician's mind as well as dentist's (Fejerskov \& Kidd, 2003; Vadiakas, 2008):

- Infant and toddlers with prolonged breast-feeding on demand

- Infants and toddlers provided with a feeding bottle at bedtime, or bottle hung up in the cot for use during the night with a sugar-containing liquid

- Children with an increased frequency of eating because of a medical problem, e.g. gastrointestinal disease, eating disorders, uncontrolled diabetes

- Children with an increased carbohydrate intake due to a medical problem, e.g. Chron's disease, chronic renal failure, other chronic illnesses, malnutrition, or failure to welfare

- Children who are on medications causing reduced salivary flow, irradiation to the region of salivary glands

- Children on long term and/or multiple medications: Are these sugar-based and/or do they cause dry mouth?. 
Measures to reduce caries risk and/or to stop ongoing caries activity in children are:

- Number of meals and snacks should be kept on a low level.

- Low sugar consumption is desirable from a cariological point of view

- Sugars should be eliminated as fast as possible from the oral cavity. Foods needing active

- Chewing lead to an increased salivation, which is desirable.

It is neither necessary nor practical to stop children eating sweets completely. On the contrary, children should be encouraged to eat a balanced meal before any sweets are given. Friend and relatives should be encouraged to bring gifts rather than sweets. The consumption of bed-time snack or drink (other than water) should be strongly discouraged, since salivary flow is virtually absent at night and plaque $\mathrm{pH}$ may remain low for many hours.

All dental professionals are encouraged to share current best practice oral health prevention strategies with their local community medical providers especially with pediatricians (Huston \& Wood, 2009).

\subsection{Clinical use of fluorides}

There is substantial evidence that fluoride, through different applications and formulas, works to control caries development. The first observations of fluoride's effects on dental caries were linked to fluoride naturally present in the drinking water, and then from controlled water fluoridation programs. Other systemic methods to deliver fluoride were later suggested, including dietary fluoride supplements such as salt and milk. These systemic methods are now being questioned due to the fact that many studies have indicated that fluoride's action relies mainly on its post-eruptive effect from topical contact with the tooth structure. It is known that even the methods of delivering fluoride known as 'systemic' act mainly through a topical effect when they are in contact with the teeth. The effectiveness of water fluoridation in many geographic areas is lower than in previous eras due to the widespread use of other fluoride modalities. Nevertheless, this evidence should not be interpreted as an indication that systemic methods are no longer relevant ways to deliver fluoride on an individual basis or for collective health programs. Caution must be taken to avoid excess ingestion of fluoride when prescribing dietary fluoride supplements for children in order to minimize the risk of dental fluorosis, particularly if there are other relevant sources of fluoride intake - such as drinking water, salt or milk and/or dentifrice (Sampaio et al., 2011; Jimenez-Farfan et al., 2011). Safe and effective doses of fluoride can be achieved when combining topical and systemic methods. Before considering supplementing fluoride, recommendations on how to avoid excessive fluoride intake should be followed (Buzalaf \& Levy, 2011).

\subsubsection{Communal water fluoridation}

Studies evaluating the effect of water fluoridation on dental caries show a reduction in both the primary and permanent dentitions of about $50 \%$. Community water fluoridation is safe and cost-effective and therefore, should be introduced and maintained wherever socially acceptable and feasible. The optimum fluoride concentration will normally be within the range $0.5-1.0 \mathrm{mg} / 1$ (ppm). At this currently accepted optimal level, water fluoridation will 
result in some mild enamel fluorosis (McDonagh et al., 2000). The technical operation of water-fluoridation systems should be monitored and recorded regularly to prevent toxic effects of the element.

\subsubsection{Fluoride-containing toothpaste}

Fluoride toothpaste is the most widely used method of applying fluoride to teeth by so far. It is commonly used at home. It also has been using in community and school-based preventive programs. A recent systematic review concluded its beneficial use in preventing caries in children and adolescents, but only significantly for fluoride concentrations of 1000 ppm and above (Wong et al., 2011). Brushing teeth with fluoride containing toothpaste twice per day is recommended. The patients should brush before bed as the paste provides fluoride concentrations in saliva while the child is asleep. The effectiveness of fluoride toothpaste is concentration dependent. The relative caries preventive effects of fluoride toothpastes of different concentrations increase with higher fluoride concentration. The decision of what fluoride levels to use for children under 6 years should be balanced with the risk of fluorosis (Walsh et al., 2010). Studies have shown that use of fluoride toothpaste from an earl age is associated with higher levels of very mild fluorosis. The very mild grades are not aesthetically compromising, the use of fluoride toothpastes should continue to be promoted in communities, where or not they are served with fluoridated water or salt (WHO, 1994). However, in a recent study, it was indicated that there was weak unreliable evidence that starting the use of fluoride toothpaste in children aged $<12$ months may be associated with an increased risk of fluorosis. The evidence if use begins between the age of 12 and 24 months is equivocal. If the risk of fluorosis is of concern, the fluoride level of toothpaste for young children (under 6 years of age) is recommended to be lower than 1000 parts per million (ppm). More evidence from studies with low risk of bias is needed (Rasines, 2010). The author agrees with some other author's suggestion that children under 6 should use an adult-concentration paste (1000-1500 ppm fluoride), but a small pea-sized portion of it. The child should be encouraged to spit out excess paste and not swallow it. Children's pastes (500 ppm fluoride or less) could be recommended for children at low risk of caries living in an area where the water contains fluoride (Kidd, 2005). Some conclusions made by the WHO expert committee in 1994 are everyone should be encouraged to brush Daily with a fluoride toothpaste, every effort must be made to develop affordable fluoridated toothpastes for general use in developing countries, fluoridated toothpaste tubes should carry advice that for children under the age of 6 years brushing should be supervised and only a very small amount (less than $5 \mathrm{~mm}$ ) should be placed on the brush or the chewing-stick (WHO, 1994).

\subsubsection{Professionally applied fluoride (fluoride varnish in the pediatrician office)}

It has been previously reported that fluoride varnish (a concentrated form of sodium fluoride) reduced caries in the primary dentition by $33 \%$ and in the permanent dentition by $46 \%$ when compared with placebo (Morinho et al., 2011). Therefore, their wider use is encouraged by WHO (1994). Visits to primary care physicians and pediatricians are the norm during children's first few years of life in many countries. Surveys of pediatric primary care providers suggest that they are willing to provide preventive dental care for their pediatric patients (Pierce et al., 2002). Lewis et al found that $74 \%$ of US pediatricians 
expressed a willingness to apply fluoride varnish (Lewis et al., 2000). In promoting preventive dental health, pediatricians benefit all children and particularly the underserved. Therefore, pediatricians will require adequate training in oral health in medical school, residency, and in continuing education courses. It has been recently reported that multiple applications of fluoride at the time of primary tooth emergence seem to be most beneficial to prevent dental caries formation. Referrals to dentists for treatment of existing disease detected by physicians during regular visits limited the cumulative reductions in caries-related treatments, but also contributed to improved oral health (Pahel et al., 2011). Twice yearly application of fluoride varnish is indicated for the children over 6 years exposed to a greater cariogenic challenge or (in exceptional cases) when it is difficult to control caries in children under 6 years. Non-dental health care professionals should seek a professional advice from a pediatric dentist for appropriate application of the varnish.

\subsubsection{Dietary fluoride supplements (tablets, drops, vitamins plus fluoride, lozenges)}

The recent data on the value of fluorides administered during pregnancy fails to disclose any valid evidence to support such use even in non-fluoridated areas. Fluoride ingestion by pregnant women does not benefit the teeth of their offspring, at least not the permanent teeth (Sa Roriz Fonteles et al., 2005). In a recent panel by American Dental Association Council on Scientific Affairs, the following questions were addressed about the usage of fluoride supplements: When and for whom should the supplements be prescribed, and what should be the recommended dosage schedule for them?. The panel concluded that dietary fluoride supplements should be prescribed only for children who are at high risk of developing caries and whose primary source of drinking water is deficient in fluoride (Rozier et al., 2010). Supplements if indicated should be prescribed in accordance with the dosages recommended in Table 3 (AAPD, 2002). The natural (e.g. water) and cumulative (e.g. consumption amount of fluoride-rich foods, sources of drinking water) fluoride concentrations, should be determined and analyzed before fluoride prescripton. These clinical recommendations should be integrated with the practitioner's professional judgment and the patient's needs and preferences. Providers should carefully monitor the patient's adherence to the fluoride dosing schedule to maximize the potential therapeutic benefit.

\begin{tabular}{|l|c|c|c|}
\hline \multicolumn{1}{|c|}{ Age } & $\begin{array}{c}\text { LESS than } \mathbf{0 . 3} \mathbf{~ p p m} \\
\mathbf{F}^{*}\end{array}$ & $\begin{array}{c}\mathbf{0 . 3 - 0 . 6 . p p m} \\
\mathbf{F}^{*}\end{array}$ & $\begin{array}{c}\text { MORE than 0.6 ppm } \\
\mathbf{F}^{*}\end{array}$ \\
\hline Birth-6 mos & 0 & 0 & 0 \\
\hline 6 mos-3 yrs & $0.25 \mathrm{mg}$ & 0 & 0 \\
\hline 3 yrs-6yrs & $0.50 \mathrm{mg}$ & $0.25 \mathrm{mg}$ & 0 \\
\hline 6 yrs up to at least 16 yrs & $1.00 \mathrm{mg}$ & $0.50 \mathrm{mg}$ & 0 \\
\hline
\end{tabular}

Table 3. Dietary fluoride supplementation schedule $\left({ }^{*}=\right.$ drinking water fluoride concentration).

\subsection{Sugar alcohols, casein phosphopeptides}

Partial sugar substitution with polyols is an important dietary tool in the prevention of dental caries that should be used to enhance existing fluoride-based caries prevention 
programmes. Clinical studies have shown that xylitol, a natural, physiologic sugar alcohol of the pentitol type, can be used as a safe and effective caries-limiting sweetener. Habitual use of xylitol-containing food and oral hygiene adjuvants has been shown to reduce the growth of dental plaque, to interfere with the growth of caries-associated bacteria, to decrease the incidence of dental caries, and to be associated with remineralization of caries lesions. Other sugar alcohols that have been successfully used as sugar substitutes include D-glucitol (sorbitol), which, however, owing to its hexitol nature, normally has no strong effect on the mass and adhesiveness of bacterial plaque and on the growth of mutans streptococci. A tetritol-type alditol, erythritol, has shown potential as a non-cariogenic sugar substitute. Combinations of xylitol and erythritol may reduce the incidence of caries more effectively than either alditol alone (Makinen, 2011). Traditional delivering vehicles such as chewing-gums, hard candies and mints can only provide contact of the sugar substitutes with tooth surface for a few minute or even seconds. Therefore, novel delivery vehicles are still needed for the effective delivery of sugar substitutes before they can be considered as therapeutically effective.A group of peptides, known as casein phosphor peptide (CPP), have been shown to stabilize calcium and phosphate preserving them in an amorphous or soluble form known as amorphous calcium phosphate (ACP). Calcium and phosphate are essential components of enamel and dentine and form highly insoluble complexes, but in the presence of CPP they remain soluble and biologically available. This CPP-ACP complex applied to teeth by means of chewing-gum, toothpaste, lozenges, mouth rinses, or sprays is able to adhere to the dental biofilm and enamel hydroxyapatite providing bioavailable calcium and phosphate ions. When placed on the surface of a tooth with early carious lesions, pastes with CPP-ACP complexes can prevent tooth demineralization and improve enamel remineralization and enhance fluoride activity. Therefore, use of CPP-ACP based compounds offers a potential for use in the prevention of dental caries (Llena et al., 2009). Recently, probiotics have been investigating for dental caries prevention and inhibition. In caries, there are increases in acidogenic and acid-tolerating species such as mutans streptococci and lactobacilli, although other bacteria with similar properties can also be found and bifidobacteria, non-mutans streptococci, Actinomyces spp., Propionibacterium spp., Veillonella spp. and Atopobium spp. have also been implicated as significant in the aetiology of this disease (Aas et al., 2008). Therefore, to be able to develop probiotic or prebiotic interventions for applications in dental health care and to understand their mechanisms of action and potential risks, it is essential to have a clear understanding of the oral microbiota and their functions in dental/oral health and disease. However, some products have reached the market, there remains a paucity of clinical evidence to support the effectiveness of probiotics to prevent or treat caries (Meurman \& Stomatova, 2007).

\subsection{Counseling families on basic oral hygiene}

The considerable potential of mothers should be a major focus of (oral) health professionals in developing oral health promotion programs for children and adolescents. Several maternal cognitive, behavioral, and psychosocial factors were associated with young children's brushing practices. Oral health-specific self-efficacy and knowledge measures are potentially modifiable cognitions and intervening on these factors could help foster healthy dental habits and increase children's brushing frequency early in life (Finlayson et al., 2007; Saied-Moallemi et al., 2008). 


\subsubsection{Feeding baby (Early Childhood Caries-ECC)}

Early childhood caries (ECC) is defined as the presence of 1 or more decayed (noncavitated or cavitated lesions), missing (due to caries), or filled tooth surfaces in any primary tooth in a 71-month or younger child. In children younger than 3 years of age, any sign of tooth smooth surface caries is indicative of severe early childhood caries (S-ECC) (AAPD, 2003a). ECC has been found in general population but is more prevalent in low socioeconomic groups. It is 5 times more common than asthma, 7 times more common than hay fever, and 14 times more common than chronic bronchitis (Filstrup et al., 2003). The clinical appearance of the teeth in ECC is typical and follows a specific pattern: There is usually early and progressive carious lesions of the primary upper incisors in first years of age followed by the involvement of the upper and lower first primary molars, and the upper canines and sometimes lower canines (according to the sequence of eruption). The lower incisors are usually unaffected because of salivary flow from sub-lingual glands, and the contact of the tongue and lips at the time of feeding that covers the lower incisors. Therefore, milk and carbohydrates spread over all teeth except the lower incisors and prevent pudding or gathering of milk around these teeth (Tinanoff et al., 1998). The American Academy of Pediatric Dentistry (AAPD) has recognized the unique and virulant nature of ECC and accepted it as a serious public health problem. The presence of high levels of ECC, despite a reduction in permanent-dentition caries through fluoridation of water and use of fluoridated toothpastes, begs for a broader look at social and behavioral factors that correlate with this form of the disease. ECC not only affects teeth, but also may lead to more widespread health issues such as: chewing difficulty, malnutrition, gastrointestinal disorders, delayed or insufficient growth (especially in regard to the height and/or weight gain), poor speech articulation, low self-esteem and social ostracism. Additionally, repeated prescriptions of antibiotics, severe pain, sepsis and even death may also be observed. ECC is an infectious disease. Mutans Streptococci (streptococcus mutans and Streptococcus sobrinus species) are the most likely causes ECC and Lactobacilli participates in the development of the lesions and play role in lesion progression not its initiation (Parisotto et al., 2010). Bifidobacteria are asoosicated with S-ECC. S. mutans and S. sobrinus are also associated with lesion recurrence. Diet also plays an important role in the acquisition and clinical expression of the disease. Children with S-ECC, had higher scores of cariogenic bacteria for between-meal juice, solid retentive foods, and eating frequency than caries-free children. S. mutans positive children with ECC consume more cariogenic foods compared to caries-free children (Palmer et al., 2010). Acquisition may occur via vertical (from mother to child) or horizontal transmission (transmission of microbes between members of a group) (Berkowitz, 2006). Further details on vertical transmission of microorganisms will be presented in the following section. Risk factors for ECC are cariogenic bacteria, inappropriate feeding practices, social variables (education, lack of fluoride, access to healthcare, lack of health insurance, Treatment of ECC is generally problematic and costly because the cooperation of babies is low. Additionally within the first year after dental caries treatments, $40 \%$ recurrence rate has been reported around restored teeth and occurrence of new decays is common (Graves et al., 2004). Primary pediatric care providers are more likely to have earlier contact with children. Therefore, pediatricians as well as primary care health professionals will be responsible for the prevention of ECC. The diagnosis of impaired dentition and related prevention and outcomes should be included in their curricula. Primary prevention of ECC begins in the prenatal and perinatal periods 
(include pregnancy and first month of birth) and addresses the health of both mother and infant. Mother's or caregiver's teeth must be examined infants whose mothers have high levels of untreated dental caries are at greater risk of acquiring organisms. General approach which have been used to prevent ECC include training of mothers or caregivers to follow healthy dietary and feeding habits to prevent the development of ECC, early screening for signs of caries development (starting from about 7 to 8 month of age) to identify infants who are at risk developing ECC and assisting in providing information for parents about promoting oral health. Pediatricians can give the following recommendations for prevention of ECC to mothers and caregivers (AAPD, 2003b):

- Elimination of active dental caries lesions, gingival disease,

- Using fluoride and clorhexidine (Toothpaste, mouthwash, gel, varnish),

- Twice daily tooth brushing of the dentate infant (around $7^{\text {th }}$ month of age),

- Oral health evaluation of the infant by a pediatric dentist before the first birthday,

- Infants should not be put to sleep with a bottle and nocturnal breastfeeding should be avoided after the first primary tooth begins to erupt,

- Mothers should be encouraged to have infants drink from a cup as they approach their first birthday,

- Infants should be weaned from the bottle at 12 to 14 months of age,

- An attempt should be made to assess and decrease the mother's/primary caregiver's mutans streptococci level to decrease the transmission of cariogenic bacteria,

- Stop saliva-sharing activities, such as tasting food before feeding and sharing toothbrushes.

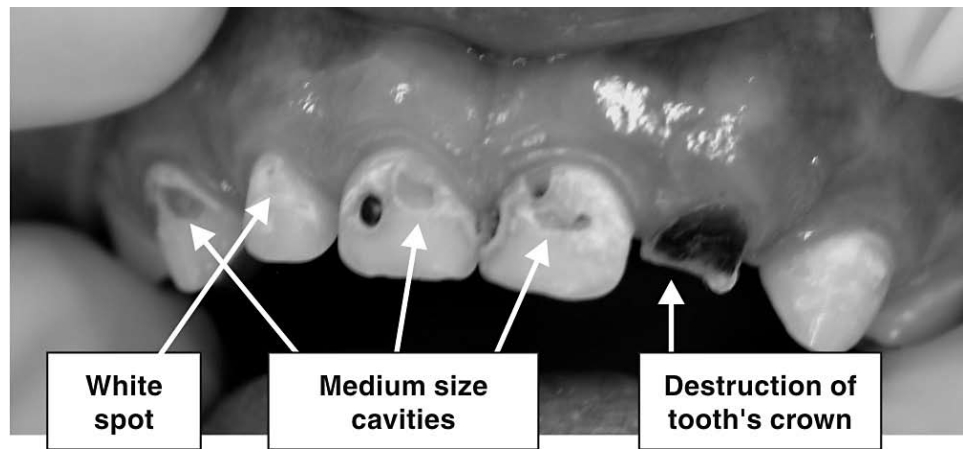

Fig. 4. Child's teeth with ECC. Observe the different phases of development (Quoted from Losso EM, Tavares MCR, da Silva JYB, Urban C (2009). Severe early childhood caries: an integral approach, J Pediatr 4, 295-300.

\subsubsection{Initial acquisition of Mutans Streptococci (MS) by infants from their mothers}

MS, consisting mainly of the species Streptococcus mutans and Streptococcus sobrinus, are commonly cultured from the mouths of infants, with prevalence of infection ranging from around $30 \%$ in 3 month old predentate children to over $80 \%$ in 24 month old children with primary teeth. MS is usually transmitted to children through their mothers. Domejean et al. (2010) indicated that MS can colonize horizontal as well as vertical transmission does occur. 
The risk of transmission increases with high maternal salivary levels of MS and frequent inoculation. Köhler \& Andreen (2010) reported that children colonised by MS at an early stage developed more caries than those colonised at a later stage and early maternal caries prevention is an efficient method to prevent early colonization of MS in their children. Factors that affect the colonization of MS may be divided into bacterial virulence, hostrelated and environmental factors. Complex interactions among these factors determine the success and timing of MS colonization in the child. As clinical studies have shown that caries risk is correlated with age at which initial MS colonization occurred, strategies for the prevention of dental caries should include timely control of colonization of the cariogenic bacteria in the mouths of young children.

\subsubsection{Mechanical and chemical home oral hygiene (reduction of dental plaque and microorganisms)}

Dentistry, particularly dentistry for children has come a long way toward reaching a ratio of $90 \%$ prevention to $10 \%$ treatment in many developed countries. At the core of this preventive approach is home oral hygiene and plaque control. The traditional focus of oral hygiene has been and will go on to be the control of the two most prevalent oral diseases, caries and periodontal disease. Although plaque control is essential for oral hygiene, it is important to realize that no clear relationship exists between plaque control and the prevention of caries (unlike with periodontal disease). As discussed previously in the section 2.1, the complex etiology of caries centers on the following factors: tooth susceptibility, bacterial plaque, refined carbohydrates, and time. Many other variables such as oral sugar clearance and salivary flow and $\mathrm{pH}$, add to the complexity of the caries process. This complex etiology helps to explain the difficulty in demonstrating a relationship between oral hygiene practices and caries prevention. Despite this ambiguity, plaque control remains an essential element for oral health. In the absence of oral hygiene dental plaque accumulates leading to shifts in bacterial populations away from those associated with health. Plaque control efforts should be directed toward two goals: (1) limiting the numbers of mutans streptococci in plaque for prevention of caries by mechanical elimination of supragingival plaque (toothbrushing) and limitation of dietary sucrose, and (2) maintaining the predominantly gram-positive flora associated with gingival health by mechanical removal of plaque from the subgingival area (flossing) on a regular basis. Brushing twice daily with fluoride toothpaste has been advocated by the profession for many years, and this behavior is a routine part of many people's behavior. This daily brushing with fluoride toothpaste is believed to be the primary reason for the decline of caries observed in many populations since the 1970s. The behavior should not be taken for granted. Children should always be asked whether, and how often, they brush their teeth and what toothpaste they use. Most toothpastes contain fluoride, but not all, and it is important to check the fluoride concentration in toothpaste to administer proper dosage to the child. The use of chemotherapeutic agents, particularly chlorhexidine, can also play a role in maintenance of gingival health. The appropriateness and effectiveness of home oral hygiene procedures change throughout childhood. It is necessary to involve the parent at some level of the oral hygiene procedures. Age categories for specific home oral hygiene recommendations are prenatal period, infants (0-1 yrs), toddlers (1-3 yrs), preschoolers (3-6 yrs), school-aged children (6-12 yrs) and adolescents (12-19 yrs). The American academy of pediatric dentistry recommends that children have their first dental visit at approximately the time of eruption of the first tooth or, at the latest, by the age of 12 months (AAPD, 
2003b). Therefore, pediatricians and primary health care providers must refer children to pediatric dentists in order to get them their regular dental visits. Objectives to be accomplished at the first visit: Instruction of the parents in the use of oral hygiene procedures, infant dental examination and fluoride status review, dietary issues related to nursing and bottle caries.

Mouthrinsing for the prevention of dental caries in children and adolescents was established as a mass prophylactic method in the 1960s and has shown average efficacy of caries reduction between $20-50 \%$. Commonly, weekly or twice monthly rinsing procedures using neutral $0.2 \% \mathrm{NaF}$ solutions have been used in schools or institutions in areas with low fluoride concentrations in the drinking water. Today, when dental caries has declined substantially in the western countries, and relatively few individuals are suffering from caries, the efficiency of large scale mouthrinsing is questioned and more individual approaches of caries prevention strategies are needed. Therefore in high risk patients, daily mouthrinses using $0.05 \% \mathrm{NaF}$ can be recommended combined with other selective preventive measures such as sugar restriction, improved oral hygiene, antibacterial treatments, and so forth. Mouthrinsing solutions have therefore been combined with antiplaque agents like chlorhexidine and other agents which can improve the caries preventive effect in high caries risk patients. Other agents than sodium fluoride have been used, such as stannous and amine fluoride with proven clinical effects. However, although a series of new formulas of mouthrinses containing fluoride combined with different antiplaque agents have shown promising antibacterial and antiplaque efficacy, their longterm clinical effects are sparsely documented. Acute and chronic side effects from established and recommended mouthrinsing routines are extremely rare but ethanol containing products should not be recommended to children for long-term use. (FDI Commision, 2002).

\section{Clinical assessment and management of the oral environment in a child patient receiving cancer treatment}

\subsection{The impact of cancer therapies on the oral cavity}

The likelihood is high that aggressive cancer treatment will have toxic effects on normal cells as well as cancer cells. The gastrointestinal tract, including the mouth, is particularly prone to damage. This is true whether the treatment is radiation or chemotherapy. Most patients being treated for head and neck cancer will experience some oral complications, and while most of these are manageable, complications can sometimes become severe enough that treatment must be completely stopped. In addition, surgical solutions to tumor removal may lead to oral and nutritional problems as well. The most common oral problems occurring after radiation and chemotherapy are mucositis (an inflammation of the mucous membranes in the mouth), infection, pain, and bleeding. Other possible complications might include dehydration and malnutrition, commonly brought on by difficulties in swallowing (dysphagia). Radiation therapy to the head and neck may injure the glands that produce saliva (xerostomia), or damage the muscles and joints of the jaw and neck (trismus). These treatments may also cause hypovascularization (reduction in blood vessels and blood supply) of the bones of the maxilla or mandible (the bones of the mouth). In addition, treatments may affect other forms of dental disease (caries, or soft tissue complications), or even cause bone death (osteonecrosis). By identifying patients at risk for oral complications, health care providers are able to start preventive measures before cancer therapy begins, 
reducing the occurrence of problems brought about by different treatment modalities. The most important risk factors leading to problems are oral or dental disease that already exists, and poor oral care during cancer therapy. Other risk factors include the type of cancer, the chemotherapy type and schedule used, the area irradiated and how much radiation is given, how low blood counts are decreased and for how long, the patient's age, and the general condition of the patient's health pre-treatment. Pre-existing oral conditions may increase the risk of infection or other problems. Problems such as caries, calculus and tartar on the teeth, broken (fractured) teeth, the condition and quality of existing dental repairs such as crowns or fillings, periodontal disease, and appliances such as removable fixtures, or orthodontic brackets can make therapy more difficult later on. Bacteria and fungi can live in the mouth, and may develop into an infection when the immune system is not working well, or when white blood cell counts are low. Both of these factors can be caused by the treatment methods used. Where the gums (gingiva) or other soft tissues are irritated, tissues can thin and waste away, causing sores in the mouth. These complications can result in a significant reduction in the quality of life for the patient.

\subsection{Oral mucositis}

\subsubsection{What is oral mucositis?}

Mucositis is a common toxicity associated with both chemotherapy, and head and neck radiation used for the treatment of cancer (Scully et al., 2003, 2004). It is characterized by ulceration in the oro-oesophageal and gastrointestinal mucosae that results in pain, dysphagia, diarrhoea and dysfunction depending on the tissue affected (Sonis \& Fey, 2002). Oral mucositis results in severe discomfort and impairs patients' ability to eat, swallow and talk. Concomitant therapy-induced myelosuppression places patients at significant risk of bacteraemia and sepsis from oral microorganisms resulting in increased days of fever, antibiotic use and hospitalization (Donnelly et al., 1995). Historically, mucositis has been associated with particular high-risk groups such as patients being irradiated for cancers of the head and neck, individuals receiving conditioning regimens for stem cell transplant that include total body irradiation or high dose melphalan and patients receiving specific induction protocols for acute leukaemia. Mucositis has been consistently reported to occur in at least $75 \%$ of treated patients in these groups. Radiation-induced mucositis occurs in almost all patients who are treated for cancers of the mouth, oropharynx and nasopharynx, and in approximately two-thirds of those treated for cancers of the hypopharynx or larynx. Mucositis risk and severity are determined by the treatment dose, radiation field size and fractionation schedules prescribed for individual patients. Hyperfractionated schedules and combination of radiation with chemotherapy increase the prevalence, severity and duration of mucositis. In patients receiving cancer chemotherapy, the frequency and severity of mucositis is mainly determined by the type(s) and dose of cancer chemotherapeutic agents used. five-fluorouracil (5-FU), cisplatin, etoposide and melphalan are particularly stomatotoxic (Chi et al., 1995; Pico et al., 1998) and mucositis is common with doxorubicin, vinblastine, taxanes and methotrexate, but uncommon with asparaginase and carmustine (Symonds, 1998). Finally, mucositis is seen in $75-99 \%$ of patients receiving conditioning regimens for haemopoietic stem cell transplantation (HSCT) particularly in those that combine total body irradiation (TBI) and chemotherapy (Blijlevens et al, 2000). Mucositis is the most common symptom and distressing complication of HSCT (Bellm et al., 2000), and some $30-50 \%$ of patients with HSCT complain that mucositis is their most significant toxicity. The only independent risk factor identified for mucositis is the conditioning 
regimen: high-dose melphalan (HDM) regimens exceed busulphan, busulphancyclophosphamide, cyclophosphamide-TBI, cyclophosphamide-carmustine (BCNU) and cyclophosphamide-etoposide-carmustine (Wardley et al., 2000).

\subsubsection{Clinical diagnosis}

Diagnosis of mucositis is clinical and based on the use of known stomatotoxic therapy, and the appearance, timing and location of oral lesions. Chemotherapy-induced mucositis occurs on the movable mucosae, rarely affecting the dorsum of the tongue, the hard palate or the gingiva. Radiation-induced mucositis also affects the movable mucosae and may involve the hard palate, albeit rarely. Infections and graft-versus-host disease (GVHD) are the most common differential diagnoses. Viral infections differ clinically from mucositis in that they are typically croppy, localized and involve keratinized mucosa of the hard palate, gingival and dorsal tongue and their onset often coincides with fever. Culture or exfoliative cytology at the time of lesion presentation is prudent. Graft-vs-host disease is limited to patients who have received allogeneic HSCT and develops following haematologic recovery (beyond 21 days after transplant) and typically results in dramatic oral lesions that are often lichenoid in character, sometimes also with xerostomia (Woo et al., 1997). Neutropenia, induced by chemotherapy, may be associated with necrotizing gingivitis.

The early clinical sign of mucositis is erythema presenting about 4-5 days following chemotherapy infusion or at cumulative doses of head and neck radiation of about $10 \mathrm{~Gy}$. Patients also often complain of burning and intolerance of spicey foods at this stage. Seven to 10 days after chemotherapy or at cumulative radiation doses of $30 \mathrm{~Gy}$, ulcers develop, resulting in marked discomfort, often requiring opioid intervention and in many cases causing patients to alter their diet. In the case of chemotherapy-induced mucositis, lesions are seen mostly on the movable mucosae of the buccal mucosae and lateral and ventral surfaces of the tongue. The hard palate and gingiva appear not susceptible to chemotherapy-induced mucositis. In contrast, radiation-induced mucositis may involve any radiation-exposed area, including the hard palate, albeit rarely. Chemotherapy-induced mucositis lasts approximately 1 week and generally heals spontaneously by 21 days after infusion. Radiation-induced mucositis stays at a peak for at least 2 weeks following the completion of radiotherapy (typically 60-70 Gy). As a result, it is not uncommon for patients receiving radiotherapy for cancers of the mouth and contiguous areas, to have severe ulcerative oral mucositis persisting for 5-7 weeks. Chronic mucositis following radiation therapy does occur, but rarely. A large number of mucositis scoring systems have been devised (summarized by Sonis et al, 2004) but most lack standardization or validation. The two most commonly used scoring tools to describe toxicity are the WHO and the National Cancer Institute (NCI) common terminology criteria for adverse events (Table 4).

\begin{tabular}{|l|l|}
\hline Grade & Clinical features \\
\hline 0 & - \\
\hline 1 & Soreness/erythema \\
\hline 2 & Erythema, ulcers but able to eat solids \\
\hline 3 & Ulcers but requires liquid diet \\
\hline 4 & Oral alimentation not possible \\
\hline
\end{tabular}

Table 4. WHO Mucositis scale (WHO, 1979). 


\subsubsection{Prevention and treatment options}

There are a number of strategies adopted by oncologists to minimize the adverse effects of cancer therapy such as dose reduction, and other preventive treatment options. For example, leucovorin has been used for years to minimize the mucositis resulting from use of 5-FU (Lalla and Peterson, 2005). These are the province of oncologists and are not discussed further here. There has been a range of interventions developed for prophylaxis of oral mucositis but a more rational approach may be warranted. Indeed, there are very few randomized controlled double-blind trials (RCTs) assessing most of the interventions. A recent Cochrane review (Worthington, 2011) concluded that cryotherapy (ice chips) and Keratinocyte Growth Factor (Palifermin $(\circledR)$ ) have shown some evidence of benefit in the prevention of mucositis. There is weaker less reliable evidence of a benefit associated with aloe vera, amifostine, intravenous glutamine supplementation, granulocyte-colony stimulating factor, honey, laser, polymixin/tobramycin/amphotericin (PTA) lozenges and sucralfate. There is no evidence that chlorhexidine is more effective that placebo and this intervention should not be used in the preventionofmucositis.

The outcomes from studies testing GM-CSF, benzydamine hydrochloride or amifostine are mixed. (Mascarin et al, 1999; Tejedor et al, 2000). Benzydamine $\mathrm{HCl}$ has been shown in single centre studies and in a multicentre double blind randomized placebo controlled trial in radiation therapy to reduce the intensity and duration of mucosal damage as well as to delay the need to use systemic pain-relievers including opioids (Epstein et al., 1989, 2001). Benzydamine was not effective however, in patients receiving accelerated radiotherapy doses of more than 220 cGy. A preliminary study indicated that the severity of oral mucositis, both objective and subjective, in HSCT patients may be reduced by $0.1 \%$ topical tretinoin cream which has antiinflammatory activity, administered daily from the beginning of the HCST conditioning until marrow engraftment (Cohen et al., 1997). Local antimicrobials containing amphotericin, polymixin and tobramycin may have some activity (Bondi et al., 1997). Small single centre trials show that the incidence, severity and duration of radiochemotherapy-induced mucositis can be significantly reduced by oral rinsing with povidone iodine performed in addition to the standard prophylaxis scheme (Adamietz et al. 1998). Mixed results have been seen with oral glutamine, which is involved in protein and nucleic acid synthesis: one group showed a decrease in the severity and duration of oropharyngeal mucositis in autologous HSCT patients but not in allogeneic HSCT patients. It is possibly because of interaction with methotrexate (Anderson et al., 1998a,b). While similar results were shown in a trial of intravenous glutamine in HSCT (MacBurney et al., 1994), and from an uptake-enhanced glutamine suspension used orally (Peterson, 2006), others have found no benefit (Schloerb \& Skikne, 1999). Mucositis invariably requires systemic analgesics, adjunctive medications, physical therapy and psychologic therapy in addition to oral care. A recent Cochrane review (Worthington, 2004) concluded that there was no evidence that patient controlled analgesia (PCA) is better than continuous infusion method for controlling pain, but less opiate was used per hour, and duration of pain was shorter, for PCA. Only weak and unreliable evidence that allopurinol mouthwash, vitamin E, immunoglobulin or human placental extract improve or eradicate mucositis.

Pain from established mucositis can be reduced by systemic analgesics with non-steroidal agents and othernon-opiods used first, combined with opioids such as morphine and hydromorphone when pain is severe. In the in-patient setting, PCA provides the most effective pain control with lower total doses of opioid. Topical analgesics may combat pain and dysphagia when used prior to meals. Capsaicin may also provide analgesia (Berger et 
al., 1995). Cubukcu \& Sevinir (2007) used debridement technique to promote healing of established mucositis and to alleviate symptom clusters in a group of children who were on induction chemotherapy. They concluded that debridement promoted resolution and decreased the severity of oral mucositis significantly. Thus, the subjects had less oral discomfort, pain, and nutritional difficulties. In general, mucositis should be treated conservatively to avoid further tissue irritation and damaging the remaining cells from which the epithelium will regenerate. Plaque control and oral hygiene should be maintained with careful tooth brushing (Borowski et al, 1994). The potential benefit of prophylactic rinses with chlorhexidine may be to control plaque levels, gingivitis, reduce caries risk and oropharyngeal candidosis, rather than any direct effect upon oral mucositis. The patient should be advised to take a soft bland diet, avoiding irritants such as tobacco, alcohol or spices. Nutrition should be maintained.

\section{Conclusion}

Tooth caries (decay) remains a substantial problem in young children and is made worse by existing barriers that prevent them from obtaining dental care. Because most children are exposed to medical care but not dental care at an early age, pediatricians have the opportunity to play an important role in helping children and their families gain access to dental care. Instructional efforts to increase pediatricians' dental knowledge or opinions of the importance of oral diseases are unlikely to be effective in increasing dental referral unless they include methods to increase confidence in providers' ability to identify and appropriately refer children with disease. Pediatricians can provide oral health promotion and disease prevention activities, thereby eliminating or delaying dental disease and the need for treatment at a very young age.

\section{References}

Aas JA, Griffen AL, Dardis SR, Lee AM, Olsen I (2008). Bacteria of dental caries in primary and permanent teeth in children and young adults. J Clin Microbiol 46, 4 (Jan 2008), 1407-1417, ISSN 0095-1137.

Adamietz IA, Rahn R, Bottcher HD, Schafer V, Reimer K, Fleischer W (1998). Prophylaxis with povidone-iodine against induction of oral mucositis by radiochemotherapy. Support Care Cancer 6, 4 (Jul 1998), 373-377, ISSN 0941-4355.

Ahola AJ, Yli-Knuuttila H, Suomalainen T, Poussa T, Ahlström A, Meurman JH, Korpela R (2002). Short-term consumption of probiotic-containing cheese and its effect on dental caries risk factors. Arch Oral Biol 47, 11 (Nov 2002), 799-804, ISSN 0003-9969.

Alaluusa S, Kiviranta H, Leppanilmi A (2002). Natal and neonatal teeth in relation to environmental toxicants. Pediatr Res 52, 5 (Nov 2002), 652-655, ISSN 0031-3998.

Almonaitiene R, Balciuniene I, Tutkuviene J (2010). Factors influencing permanent teeth eruption. Part One-general factors. Stomatologija 12, 3, 67-72, ISSN 1392-8589.

AlQahtani SJ, Hector MP, Liversidge HM (2010). Brief communication: The London atlas of human dental development and eruption. Am J Phys Anthropol 142, 3 (Jul 2010), 481-490, ISSN 0002-9483.

American Academy of Pediatric Dentistry (2003b). Clinical guidelines on infant oral healthcare, accessed 3/29/2010, avaliable from:

http://www.aapd.org/media/Policies_Guidelines/G_InfantOralHealthCare.pdf. 
American Academy of Pediatric Dentistry, Originating Group and Review Council (2003a). Policy on ECC: Classification, consequences, and preventive strategies. Pediatr Dent 25, 24-28, ISSN 0164-1263.

American Academy of Pediatric Dentistry: Guidelines on infant oral health care (2002). Pediatr Dent (supplemental issue: reference manual 2002-2003) 24,47, ISSN 01641263.

Anderson PM, Schoreder G, Skubitz KM (1998). Oral glutamine reduces the duration and severity of stomatitis after cytotoxic cancer chemotherapy. Cancer 83, 1433-1439, ISSN 0008-543X.

Bellm LA, Epstein JB, Rose-Ped A, Martin P, Fuchs HJ (2000). Patient reports of complications of bone marrow transplantation. Support Care Cancer 8, 1 (Jan 2000), 33-39, ISSN 0941-4355.

Berger A, Henderson M, Nadoolman W, Duffy V, Cooper D, Saberski L, Bartoshuk L (1995). Oral capsaicin provides temporary relief for oral mucositis pain secondary to chemotherapy/radiation therapy. J Pain Symptom Manage 11, 5 (May 1995), 331, ISSN 0885-3924.

Berkowitz RJ (2006). Mutans streptococci: Acquisition and transmission. Pediatr Dent 28, 2 (Mar-Apr 2006), 106-109, ISSN 0164-1263.

Blijlevens NM, Donnely JP, De Pauw BE (2000). Mucosal barrier injury: biology, pathology, clinical counterparts and consequences of intensive treatment for hematological malignancy: an overview. Bone Marrow Transplant 25, 12 (Jun 2000), 1269-1278, ISSN 0268-3369.

Bondi E, Baroni C, Prete A, Gatti M, Carrassi A, Lodi G, Porter SR (1997). Local antimicrobial therapy of oral mucositis in pediatric patients undergoing bone marrow transplantation. Oral Oncol 33, 5 (Sep 1997), 322-326, ISSN 1368-8375.

Borowski B, Benhamou E, Pico JL, Laplanche A, Margainaud JP, Hayat M (1994). Prevention of oral mucositis in patients treated with high-dose chemotherapy and bone marrow transplantation: a randomised controlled trial comparing two protocols of dental care. Eur J Cancer B Oral Oncol 30B, 2:93-7, ISSN 0964-1955.

Buzalaf MA, Levy SM. Fluoride intake of children. Monogr Oral Sci 22, (Jun 2011), 1-19, ISSN 0077-0892.

Carlstedt K, Krekmanova L, Dahllöf G, Ericsson B, Braathen G, Modéer T (1996). Oral carriage of Candida species in children and adolescents with Down's syndrome. Int J Paediatr Dent 6,2 (Jun 1996), 95-100, ISSN 0960-7439.

Cetinkaya M, Oz FT, Orhan AI, Orhan K, Karabulut B, Ilk O (2011). Prevalence of oral abnormalities in a Turkish newborn population. Int Dent J 61,2 (Apr 2011), 90-100, ISSN 0020-6539.

Chi KH, Chen CH, Chan WK (1995). Effect of granulocyte-macrophage colony stimulating factor on oral mucositis in head and neck cancer patients after cisplatin, fluoruracil, and leucovorin chemotherapy. J Clin Oncol 13, 10 (Oct 1995), 2620-2628, ISSN 0732$183 X$.

Cichon P, Crawford L, Grimm WD (1998). Early-onset periodontitis associated with Down's syndrome: clinical interventional study. Ann Periodontol 3,1 (Jul 1998), 370-380, ISSN 1553-0841. 
Cohen G, Elad S, Or R, Galili D, Garfunkel AA (1997). The use of tretonin as oral mucositis prophlaxis in bone marrow transplantation patients: a preliminary study. Oral Dis 3, 4 (Dec 1997), 243-246, ISSN 1354-523X.

Conley H, Steflik DE, Singh B, Hoffman WH (1990). Clinical and histological findings of the dentition in a hypopituitary patient: report of case. ASDC J Dent Child 57,5 (SeptOct 1990), 376-379, ISSN 1945-1954.

Cubukcu CE, Sevinir B (2007). Debridement could be a solution to promote healing of established oral mucositis in children. Eur Arch Paediatr Dent 8, 2 (Jun 2007), 105-12, ISSN 1818-6300.

Cunha RF, Boer FA, Torriani DD, Frossard WT (2001). Natal and neonatal teeth: review of the literature. Pediatr Dent 23,2 (Marc-Apr 2001), 158-162, ISSN 0164-1263.

Dally A (1996). The lancet and the gum-lancet: 400 years of teething babies. Lancet 348, 9043 (Dec 1996), 1710-1711, ISSN 0140-6736.

Davidovich E, Aframian DJ, Shapira J, Peretz B (2010). A comparison of sialochemistry, oral $\mathrm{Ph}$, and oral health status of Down syndrome children to healthy children. Int $J$ Paediatr Dent 20, 4 (Jul 2010), 235-241, ISSN 0960-7439.

Demirjian A, Levesque GY, (1980). Sexual differences in dental development and prediction of emergence. J Dent Res 59, 7, 1110-1122, ISSN 0022-0345.

Doméjean S, Zhan L, DenBesten PK, Stamper J, Boyce WT, Featherstone JD (2010). Horizontal transmission of mutans streptococci in children. J Dent Res 89, 1 (Jan 2010), 51-55, ISSN 0022-0345.

Donelly JP, Dompeling EC, Meis JF, De Pauw BE (1995). Bacteriemia due to oral viridans streptococci in neutropenic patients with cancer: Cytostatics are a more important risk factor than antibacterial prohylaxis. Clin Infect Dis 20, 2 (Feb 1995), 469-470, ISSN 1058-4838.

Epstein JB, Silverman S Jr, Paggiarino DA, Crockett S, Schubert MM, Senzer NN, Lockhart PB, Gallagher MJ, Peterson DE, Leveque FG (2001). Benzydamine $\mathrm{HCl}$ for prophylaxis of radiation-induced oral mucositis: results from a multicenter, randomized, double-blind, placebo-controlled trial. Cancer 92, 4 (Aug 2001), 875885, ISSN 0008-543X.

Epstein JB, Stevenson-Moore P, Jackson S, Mohamed JH, Spinelli JJ (1989). Prevention of oral mucositis in radiation therapy: a controlled study with benzydamine hydrochloride rinse. Int J Radiat Oncol Biol Phys 16, 6 (jun 1989), 1571-1575, ISSN 0360-3016.

Ertugrul F, Tuncer AV, Sezer B (2002). Infraocclusion of primary molars: a review and report of a case. ASDC Dent Child 69, 2 (May-Aug 2002), 166-171, ISSN 1945-1954.

FDI Commision (2002). Mouthrinses and dental caries. Int Dent J 52, 5 (Oct 2002), 337-345, ISSN 0020-6539.

Fejerskov O, Kidd EAM (2003). The role of dietary carbohydrate, In: Essentials of Dental Caries-the disease and its management. Kidd EAM, pp.7-8, Oxford University Press, ISBN 0198529783, New York.

Feldens CA, Faracol M, Ottoni AB, Feldens EG, Vitolo MR (2010). Teeting symptoms in the first year of life and associated factors: a cohort study. J Clin Pediatr Dent 34, 3 (Spring 2010), 201-206, ISSN 1053-4628.

Filstrup SL, Briskie D, Fonseca M, Lawrence L, Wandera A, Ingleheart MR (2003). ECC and quality of life: child and parent perspectives. Pediatr Dent 25, 5 (Sept-Oct 2003), 431440, ISSN 0164-1263. 
Finlayson TL, Siefert K, Ismail AI, Sohn W (2007). Maternal self-efficacy and 1-5-year-old children's brushing habits. Community Dent Oral Epidemiol 35, 4 (Aug 2007), 272-81, ISSN 0301-5661.

Fromm A (1967). Epstein's pearls, Bohn's nodules and inclusion cysts of the oral cavity. J Dent Child 34, 4 (Jul 1967), 275-287, ISSN 0022-0353.

Gladen BC, Taylor JS, Wu YC, Ragan NB, Rogan WJ, Hsu CC (1990). Dermatological findings in children exposed transplacentally to heat-degredated polychlorinated biphenyls in Taiwan. Br J Dermatol 122, 6 (Jun 1990), 799-808, ISSN 0007-0963.

Graves CE, Berkowitz RJ, Proskin HM, Chase I, Weinstein P, Billings R (2004). Clinical outcomes for ECC: Influence of aggresive dental surgery. J Dent Child 71, 2 (MayAug 2004), 114-117, ISSN 1551-8949.

Gupta SK, Saxena P, Jain S, Jain D (2011). Prevalence and distribution of selected developmental dental anomalies in an Indian population. J Oral Sci 53 ,2, 231-238, ISSN 1343-4934.

Huston J, Wood AJ (2009). Sharing early preventive oral health with medical colleagues: a dental pain prevention strategy. J Calif Dent Asssoc 37, 10 (Oct 2009), 723-34, ISSN 1343-4934.

Jara L, Ondarza A, Blanco R, Valenzuela C (1993). The sequence of eruption of the permanent dentition in a children sample with Down's syndrome. Arch Oral Biol 38, 1 (Jan 1993), 85-89, ISSN 0003-9969.

Jimènèz- Farfan MD, Hernandez-Guerrero JC, Juarez-Lopez LA, Jacinto-Aleman LF, de la Fuente-Hernandez J (2011). Fluoride consumption and its impact on oral health. Int J Environ Res Public Health 8, 1 (Jan 2011), 148-160, ISSN 1660-4601.

Kidd, EAM (2005). Classification of dental caries, In: Essentials of dental caries: the disease and its management. Kidd EAM pp.13 and 118, Oxford University Press, ISBN 0198529783, New York.

Köhler B, Andreen I (2010). Mutans streprococci and caries prevalence in children after early maternal caries prevention: a follow-up at eleven and fifteen years of age. Caries Res 44, 5 (Sept 2010), 453-458, ISSN 0008-6568.

Lalla RV, Peterson DE (2005). Oral mucositis. Dent Clin North Am 49, 1 (Jan 2005), 167-184, ISSN 0011-8532.

Leung AK (1989). Teething. Am Fam Physician 39, 2 (Feb 1989), 131-134, ISSN 0002-838X.

Lewis CW, Grosman DC, Domoto PK, Deyo RA (2000). The role of the pediatrician in the oral health of children: A national survey. Pediatrics 106, 6 (Dec 2000), 84, ISSN 1098-4275.

Llena C, Forner L, Baca P (2009). Anticariogenicity of casein phoshopeptide amorphous calcium phospate: a review of the literature. J Contemp Dent Pract 10, 3 (May 2009), 1-9, ISSN 1526-3711.

Losso EM, Tavares MCR, da Silva JYB, Urban C deA (2009). Severe early childhood caries: an integral approach, J Pediatr (Rio J) 85, 4 (Jul-Aug 2009), 295-300, ISSN 1678-4782.

MacBurney M, Young LS, Ziegler TR, Wilmore DW (1994). A cost-evaluation of glutaminesupplemented parental nutrition in adult bone marrow transplant patients. J Am Diet Assoc 94, 11 (Nov 1994), 1263-1266, ISSN 0002-8223.

Macknin ML, Piedmonte M, Jacobs J, Skibinski C (2000). Symptoms associated with infant teething: a retrospective study. Pediatrics 105, 4 (Apr 2000), 747-752, ISSN 0031-4005. 
Makinen KK (2011). Sugar alcohol sweeteners as alternatives to sugar with special consideration of xylitol. Med Princ Pract 20, 4 (May 2011), 303-320, ISSN 1011-7571.

Marakoglu K, Percin EF, Marakoglu I, Gursoy UK, Goze F (2004). Anencephalic infant with cleft palate and natal teeth: a case report. Cleft Palate Craniofac J 41, 4 (Jul 2004), 456458, ISSN 1055-6656.

Marinho VCC, Higgins JPT, Logan S, Sheiham A (2002). Fluoride varnishes for preventing dental caries in children and adolescents (Review). Cochrane Database Syst Rev 1, CD002284.

Marks SC Jr., Schroeder HE (1996). Tooth eruption: theories and facts. Anat Rev 245, 2 (June 1996), 374-393, ISSN 0003-276X.

Masatomi Y, Abe K, Ooshima T (1991). Unusual multiple natal teeth: case report. Pediatr Dent 13, 3 (May-June 1991), 170-172, ISSN 0164-1263.

Mascarin M, Franchin G, Minatel E, Gobitti C, Talamini R, De Maria D, Trovò MG (1999). The effect of granulocyte colony-stimulating factor on oral mucositis in head and neck cancer patients treated with hyper fractionated radiotherapy. Oral Oncol 35, 2 (Mar 1999), 203-208, ISSN 1368-8375.

McDonagh MS, Whiting PF, Wilson PM, Sutton AJ, Chestnutt I, Cooper J, Misso K, Bradley M, Treasure E, Kleijnen J (2000). Systematic review of water fluoridation. BMJ 321, 7265 (Oct 2000) :855-859, ISSN 0959-8138.

Meurman JH, Stamatova I (2007). Probiotics: contributions to oral health. Oral Dis 13, 5 (Sept 2007), 443-445, ISSN 1354-523X.

Mg'ang'a PM, Chindia ML (1990). Dental and skeletal changes in juvenile hypothyroidism following treatment: case report Odontostomatol Trop 13, 1 (Jan 1990), 25-27, ISSN 0251-172X.

Moore PA, Guggenheimer J (2008). Medication-induced hyposalivation: etiology, diagnosis and treatment. Compend Contin Educ Dent 29, 1 (Jan-Feb 2008), 50-55, ISSN 15488578.

Morinushi T, Lopatin DE, Van Poperin N (1997). The relationship between gingivitis and the serum antibodies to the microbiota associated with periodontal disease in children with Down's syndrome. J Periodontol 68, 7 (Jul 1997), 626-631, ISSN 0022-3492.

Moynihan PJ (2002). Dietary advice in dental practice. Br Dent J 193, 10 (Nov 2002), 563-568, ISSN 0007-0610.

Ondarza A, Jara L, Muñoz P, Blanco R (1997). Sequence of eruption of deciduous dentition in a Chilean sample with Down's syndrome. Arch Oral Biol 42, 5 (May 1997), 401406, ISSN 0003-9969.

Padmanabhan MY, Pandey RK, Aparna R, Radhakrishnan V (2010). Neonatal sublingual traumatic ulceration - case report \& review of the literature. Dent Traumatol 26, 6 (Dec 2010), 490-5, ISSN 1600-9657.

Pahel BT, Rozier RG, Stearns SC, Quinonez RB (2011). Effectiveness of preventive dental treatments by physicians for young medicaid enrollees. Pediatrics 127, 3 (Feb 2011), 682-689, ISSN 0031-4005.

Palmer CA, Kent R Jr, Loo CY, Hughes CV, Stutius E, Pradhan N, Dahlan M, Kanasi E, Arevalo Vasquez SS, Tanner AC (2010). Diet and caries-associated bacteria in severe early childhood caries. J Dent Res 89, 11 (Sept 2010), 1224-1229, ISSN 0022-0345. 
Parisotto TM, Steiner-Oliveira C, Silva CM, Rodrigues LK, Nobre-dos-Santos M. (2010). Early childhood caries and mutans streptococci: a systematic review. Oral Health Prev Dent 8, 1, 59-70, ISSN 1602-1622.

Petersen PE. (2003). The world oral health report: Continuous improvement of oral health in the 21st century--the approach of the WHO Global Oral Health Programme. Community Dent Oral Epidemiol 31, 1 (Dec 2003), 3-24, ISSN 0301-5661.

Peterson DE (2006). New strategies for management of oral mucositis in cancer patients. J Support Oncol 4, 2 (Feb 2006), 9-13, ISSN 1544-6794.

Philbrick WM, Dreyer BE, Nakchbandi IA, Karaplis AC (1998). Parathyroid hormone-related protein is required for tooth eruption. Proc Natl Acad Sci USA 95, 20 (Sep 1998), 11846-11851, ISSN 0027-8424.

Pico JL, Avila-Garavito A, Naccache P (1998). Mucositis: its occurence, consequences, and treatment in the oncology setting. Oncologist 3, 6, 446-451, ISSN 1549-490X.

Pierce KM, Rozier G, Vann WF Jr. (2002). Accuracy of pediatric primary care providers' screening and referral early childhood caries. Pediatrics 109, 5 (May 2002), 82, ISSN 1098-4275.

Pridds RW, Price C (1984). The so-called eruption sequestrum. Oral Surg 58, 3 (sep 1984), 321-326, ISSN 0030-4220.

Profit WR, Fraizer-Bowers SA (2009). Mechanisms and control of tooth eruption: overview and clinical implications. Orthod Craniofac Res 12, 2 (May 2009), 59-66, ISSN 16016343.

Rasines G (2010). Using a fluoridated supplement with a high fluoride concentration in children aged under 6 years may increase the risk of fluorosis. Evid Based Dent 11, 1, 8-9, ISSN 1476-5446.

Richardsson A, Deussen FF (1994). Facial and dental anomalies in cleidocranial dysplasia: a study of 17 cases. Int J Paediatr Dent 4, 4 (Dec 1994), 225-231, ISSN 0960-7439.

Rozier RG, Adair S, Graham F, Iafolla T, Kingman A, Kohn W, Krol D, Levy S, Pollick H, Whitford G, Strock S, Frantsve-Hawley J, Aravamudhan K, Meyer DM (2010). Evidence based clinical recommendations on the prescription of dietary fluoride supplements for caries prevention: a report of the ADA council on scientific affairs. J Am Dent Assoc 141, 12 (Dec 2010), 1480-1489, ISSN 1943-4723.

Sa Roriz Fonteles C, Zero DT, Moss ME, Fu J (2005). Fluoride concentrations in enamel and dentin of primary teeth after pre- and postnatal fluoride exposure. Caries Res 39, 6 (Nov-Dec 2005), 505-508, ISSN 0008-6568.

Saied-Moallemi Z, Virtanen JI, Ghofranipour F, Murtomaa H (2008). Influence of mothers' oral health knowledge and attitudes on therir children's dental health. Eur Arch Paediatr Dent 9, 2 (Jun 2008), 79-83, ISSN 1818-6300.

Sampaio FC, Levy SM (2011). Systemic fluoride. Monogr Oral Sci 22 (Jun 2011), 133-45, ISSN 0077-0892.

Schloerb PR, Skikne BS (1999). Oral and parental glutamine in bone marrow transplantation: a randomized, double blind study. JPEN J Parenter Enteral Nutr 23, 3 (May-June 1999), 117-122, ISSN 0148-6071.

Scully C, Epstein J, Sonis S (2003). Oral mucositis: a challenging complication of radiotherapy, chemotherapy, and radiochemotherapy. Part 1, pathogenesis and prophylaxis of mucositis. Head Neck 25, 12 (Dec 2003), 1057-1070, ISSN 1043-3074. 
Scully C, Epstein J, Sonis S (2004). Oral mucositis: a challenging complication of radiotherapy, chemotherapy, and radiochemotherapy. Part 2, diagnosis and management of mucositis. Head Neck 26, 1 (Jan 2004), 77-84, ISSN 1043-3074.

Seminario AL, Ivancakova R (2004). Natal and neonatal teeth. Acta Medica 47, 4, 229-233, ISSN 1211-4286.

Sonis ST (2002). The biological role of nuclear factor- $\kappa \beta$ in disease and its potential involvement in mucosal injury associated with antineoplastic therapy. Crit Rev Oral Biol Med 13, 5, 300-309, ISSN 1045-4411.

Sonis ST, Elting LS, Keefe D, Peterson DE, Schubert M, Hauer-Jensen M, Bekele BN, RaberDurlacher J, Donnelly JP, Rubenstein EB; Mucositis Study Section of the Multinational Association for Supportive Care in Cancer; International Society for Oral Oncology (2004). Perspectives on cancer therapy-induced mucosal injury: pathogenesis, measurement, epidemiology, and consequences for patients. Cancer 100, 9 (May 2004), 1995-2025, ISSN 0008-543X.

Sood S, Sood M (2010). Teething: myths and facts. J Clin Pediatr Dent 35, 1 (Fall 2010), 9-13, ISSN 1053-4628.

Spouge JD, Feasby WH (1966). Erupted teeth in the newborn. Oral Surg 22,198-208.

Starkey PE, Shafer WG (1963). Eruption sequestra in children. J Dent Child 30, 4-86.

Symonds RP (1998). Treatment-induced mucositis: an old problem with new remedies. $\mathrm{Br} \mathrm{J}$ Cancer 77, 10 (May 1998), 1689-1695, ISSN 0007-0920.

Tasanen A (1968). General and local effects of the eruption of deciduous teeth. Ann Paediatr Fenn 14,1-40.

Tejedor M, Valerdi JJ, Arias F, Dominguez MA, Pruja E, Mendez L, Illarramendi JJ (2000). Hyper fractionated radiotherapy concomitant with cisplatin and granulocyte macrophage colony-stimulating factor (Filgrastim) for laryngeal carcinomas. Cytokines Cell Mol Ther 6, 1 (Mar 2000), 35-39, ISSN 1368-4736.

Tinanoff N (1998). Introduction to the early childhood caries conference: Initial description and current understanding. Community Dent Oral Epidemiol 26,1, 5-7, ISSN 03015661.

Tsiklakis K, Patsakas A (1989). Differential diagnosis of bluish and pigmented lesions of the oral mucosa. Hell Stomatol Chron 33, 2 (Apr-Jun 1989), 113-20, ISSN 1011-4181.

Uzamis M, Olmez S, Ozturk H, Celik H (1999). Clinical and ultrastructural study of natal and neonatal teeth. J Clin Pediatr Dent 23, 3 (spring 1999), 173-177, ISSN 1053-4628.

Vadiakas G (2008). Case definition, aetiology and risk assessment of early childhood caries (ECC): a revisited review. Eur Arch Paediatr Dent 9, 3 (sep 2008), 114-125, ISSN 18186300.

Walsh T, Worthington HV, Glenny AM, Appelbe P, Morinho VC, Shi X (2010). Fluoride toothpastes of different concentrations for preventing dental caries in children and adolescents. Evid Based Dent 20, 1 (Jan 2010), 6-7, ISSN 1469-493X.

Wardley AM, Jayson GC, Swindell R, Morgenstern GR, Chang J, Bloor R, Fraser CJ, Scarffe $\mathrm{JH}$ (2000). Prospective evaluation of oral mucositis in patients receiving myeloablative conditioning regimens and haemapoietic progenitor rescue. $\mathrm{Br} J$ Haematol 110, 2 (Aug 2000), 292-299, ISSN 0007-1048.

Watkins JJ (1975). An unusual eruption sequestrum. Br Dent J 138, 10 (May 1975), 395-396, ISSN 0007-0610. 
Wise G. et al. (2002). Cellular, molecular, and genetic determinants of tooth eruption. Crit Rev Oral Biol Med 13, 4, 323-335, ISSN 1045-4411.

Wong MC, Clarkson J, Glenny AM, Lo EC, Marinho VC, Tsang BW, Walsh T, Worthington HV (2011). Cochrane reviews on the benefits/risks of fluoride toothpastes. J Dent Res 90, 5 (May 2011), 573-579, ISSN 1544-0591.

Woo SB, Lee SJ, Schubert MM (1997). Graft-vs.-host disease. Crit Rev Oral Biol Med 8, 2, $201-$ 216, ISSN 1045-4411.

World Health Organization (WHO) oral health country / area profile (2011). Geneva: WHO; available at: URL:http:/ / www.mah.se/CAAP/methods-and-indices.html.

World Health Organization (WHO) technical report series (1994). Fluorides and oral health. WHO expert committee on oral health status and fluoride use. Geneva, 846, 118, ISSN 05123054 .

World Health Organization (WHO) Technical Report Series (2003). Diet, nutrition and the prevention of chronic diseases, WHO Expert Committee. Geneva, 196 (Jan-Feb 2002), 797, ISBN 924120916 X.

Worthington HE, Clarkson JE, Eden OB (2004). Interventions for treating oral mucositis for patients with cancer receiving treatment. Cochrane Database Syst Rev 2, CD001973, ISSN 1469-493X.

Worthington HV, Clarkson JE, Bryan G, Furness S, Glenny AM, Littlewood A (2011). Interventions for preventing oral mucositis for patients with cancer receiving treatment. Cochrane Database Syst Rev. 13, 4 (Apr 2011), CD000978, ISSN 1469-493X.

Zhu J, King D (1995). Natal and neonatal teeth. ASDC J Dent Child 62, 2 (Mar-Apr 1995), 123128, ISSN 1945-1954. 


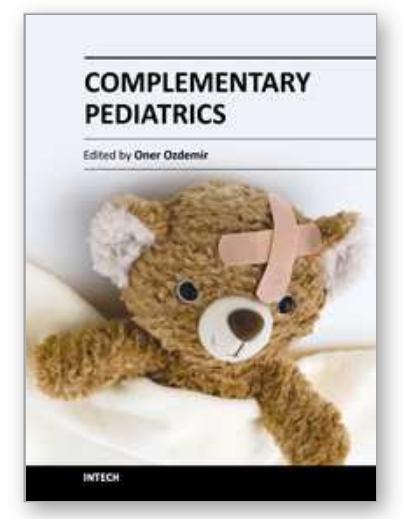

\author{
Complementary Pediatrics \\ Edited by Dr. Öner Özdemir
}

ISBN 978-953-51-0155-0

Hard cover, 354 pages

Publisher InTech

Published online 16, March, 2012

Published in print edition March, 2012

Complementary Pediatrics covers complementary issues of pediatric subspecialties consisting of ophthalmologic, surgical, psychosocial and administrative issues of frequently used medications. This book volume with its 16 chapters will help get us and patients enlightened with the new developments on these subspecialties' area.

\title{
How to reference
}

In order to correctly reference this scholarly work, feel free to copy and paste the following:

Cigdem Elbek Cubukcu (2012). What is the Role of Pediatricians on Oral Health?, Complementary Pediatrics, Dr. Öner Özdemir (Ed.), ISBN: 978-953-51-0155-0, InTech, Available from:

http://www.intechopen.com/books/complementary-pediatrics/what-is-the-role-of-pediatricians-on-oral-health-

\section{INTECH}

open science | open minds

\section{InTech Europe}

University Campus STeP Ri

Slavka Krautzeka 83/A

51000 Rijeka, Croatia

Phone: +385 (51) 770447

Fax: +385 (51) 686166

www.intechopen.com

\section{InTech China}

Unit 405, Office Block, Hotel Equatorial Shanghai

No.65, Yan An Road (West), Shanghai, 200040, China

中国上海市延安西路65号上海国际贵都大饭店办公楼405单元

Phone: +86-21-62489820

Fax: $+86-21-62489821$ 
(C) 2012 The Author(s). Licensee IntechOpen. This is an open access article distributed under the terms of the Creative Commons Attribution 3.0 License, which permits unrestricted use, distribution, and reproduction in any medium, provided the original work is properly cited. 